Session 1566

\title{
Doing Assessment During a Time of Administrative and Curricular Change
}

\author{
William Jordan, Mel Corley, and Stan Napper \\ College of Engineering and Science \\ Louisiana Tech University
}

\begin{abstract}
Our university has recently gone through the ABET EC-2000 review process. Like many other universities, we have integrated this process with our efforts to improve assessment of our academic programs and college operations. This paper documents some of the processes that we have successfully developed to deal with these issues.
\end{abstract}

There are some things that made our process significantly different from that of most other schools who have had to adapt to the new way ABET accreditation is being done. During the last 6 six years, four dramatic changes occurred within our college. We would have made these changes without the impetus of the ABET process, but these changes made the assessment process much more challenging that it would have been otherwise. In some ways the challenge helped facilitate our assessment.

The first change was the moving of the math, physics, and chemistry programs (and faculty) into our college making it the College of Engineering and Science. The second major change was the adoption in 1996 of a nontraditional, but more streamlined organizational structure. For example, we no longer have traditional departments, but have maintained traditional academic programs in mechanical engineering, biomedical engineering, etc. The third and fourth major changes came at about the same time in 1999. We had begun to create an integrated freshman and sophomore engineering program. We had a small pilot program beginning in the fall of 1997 and a larger pilot program starting in the fall of 1998. While we were in the midst of this transition, our state governing board required us to lower the number of semester hours in our programs to 128. Most of the engineering curricula required about 138 hours at that time. Faced with the mandated change in lowering the hours and the previous commitment to go to an integrated curricula, most of our programs also made significant changes in our junior and senior level courses (instead of just eliminating some courses to get to the lower level).

Managing all of these changes, and continuing to assess their impact on our programs, has proven to be a challenging task. As we developed methods to assess our programs, we also developed instruments to assess the effectiveness of individual courses. This paper will explain how this was accomplished.

"Proceedings of the 2002 American Society for Engineering Education Annual Conference \& Exposition Copyright $\odot 2002$, American Society for Engineering Education" 


\section{Changes that Occurred since the last ABET visit}

\section{A. Structural Changes}

During this time period there were two major changes to our College. There was a merger of math and science into our college to create a new College of Engineering and Science. There was also a significant restructuring of the college ${ }^{1}$. These two processes overlapped in time and are discussed in this section.

Prior to 1995, the College of Engineering had a traditional structure that included six engineering departments and a computer science department. Beginning in 1994 the College began discussions of restructuring the college to provide a more integrative and innovative environment. At the same time, the School of Science, including mathematics and statistics, chemistry, and physics, was merged with the College of Engineering to establish what is now the College of Engineering and Science. The proposed restructuring plans were discussed several times with the faculty, staff, College advisory board, and several department boards, and a new administrative structure was established for implementation in1995. The new structure is dynamic, breaking down traditional barriers to innovation and resource use. As such, the essential elements are in multi-disciplinary teams and interactions, rather than a focus on specific organizational lines and boxes. Figure 1 below shows the current administrative structure, indicating the interaction between the academic programs (faculty and students), the Leadership Team, the research centers and other interdisciplinary teams.

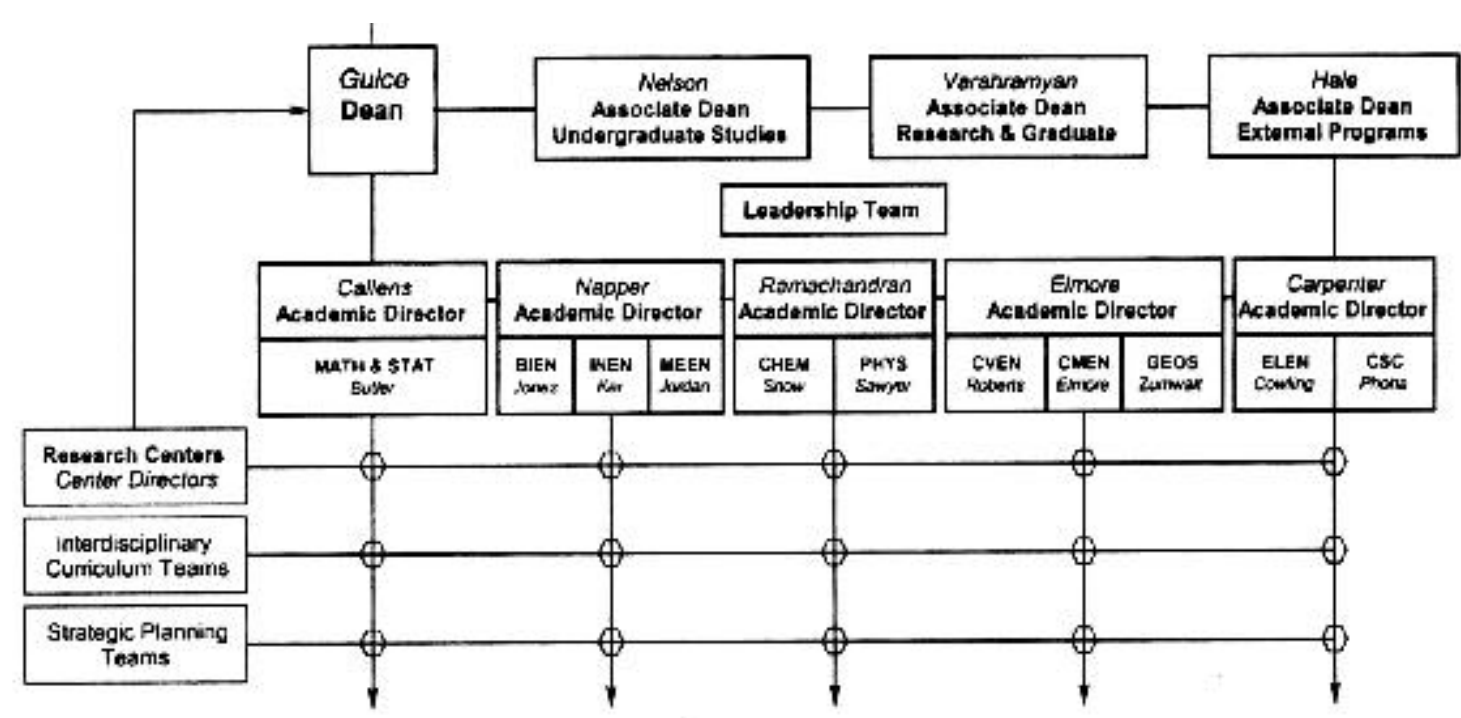

Figure 1 Organizational Structure Within the College of Engineering and Science

"Proceedings of the 2002 American Society for Engineering Education Annual Conference \& Exposition Copyright @2002, American Society for Engineering Education" 
The academic programs remain the focus of our existence. Each program has a chair, a person whose faculty job is different from that of a traditional department head. The chair is expected to spur discussions about curriculum and student issues. The program chairs have primary responsibility for updating and assessing the curriculum, coordinating student advising and recruiting, monitoring retention, assuring that degree requirements are met by graduating students, and assisting students with placement. Program chairs work with their faculty and the Academic Director to make the actual teaching assignments. Program chairs are selected for their demonstrated concern for the students, vision for improving the program as well as the entire college, and communication skills. Program chairs are provided approximately $20-40 \%$ release from teaching or other duties depending on the size of the program.

The Academic Directors are primarily responsible for faculty and staff workload assignments, budget allocations, and faculty evaluations, as well as strategic direction and promotion of cross-college collaboration. Specific teaching assignments are largely left to the program chairs, although the Leadership Team has to become involved occasionally to make sure that all teaching needs in the college are met. Academic Directors also lead interdisciplinary teams in accomplishing the College's academic program. Each Academic Director may be administratively responsible for more than one academic program. This flexible structure serves to promote cooperation across discipline lines and has reduced some of the turf issues that normally exist in a university environment.

While faculty hold appointments in specific academic disciplines such as Mechanical Engineering and Biomedical Engineering, they may be involved in one or more curriculum areas (such as the Mechanics \& Materials Team) or research centers (such as the Institute for Micromanufacturing). Each faculty member is aligned with at least one of these areas. The curricular areas referred to here include those which bridge several disciplines, such as the freshman experience, integration of senior design experiences, development of mechanics courses, etc. Some of these teams continue for more than one year, while others disband when a particular solution is developed and implemented. Some teams are self-forming clusters of faculty who chose to work together on new initiatives or pursue opportunities.

One of the objectives of the restructuring was to promote faculty and staff participation in important decision-making processes. Although the Dean and Leadership Team have final approval on all team recommendations, these recommendations have usually been accepted. There has also been more of a focus on college-wide resource sharing. For example, civil and mechanical engineering now share materials testing labs, thereby increasing the availability of equipment and reducing redundancy in new purchases.

\section{B. Creation of Integrated Freshman and Sophomore Curriculum}

"Proceedings of the 2002 American Society for Engineering Education Annual Conference \& Exposition Copyright $@ 2002$, American Society for Engineering Education", 
At the same time the structural changes were being made in our college we began to develop a curriculum reform initiative in response to the nation wide focus on change in engineering education. As aspects of the college were being integrated, it seemed only natural to extend that integration to the curriculum.

Both freshman and sophomore level integrated engineering curricula have been developed at Louisiana $\mathrm{Tech}^{2}$. These curricula are intended to provide the first two years of a true four year curriculum. A pilot group of 40 students participated in the new freshman curriculum in the 1997-1998 year. For the 1998-1999 academic year, these students enrolled in a pilot integrated sophomore program and 120 new students began the integrated freshman program. Full implementation of the integrated freshman and sophomore curricula occurred in the 1999-2000 academic year. The freshman program focuses on integration of topics between engineering, math, chemistry, and physics. The sophomore year was designed to successfully mesh with the integrated freshman curriculum and provide breadth of knowledge in a number of engineering subjects.

Although there has been some team teaching of classes, most of the courses are taught as separate classes with coordinated coverage of topics. Integration of topics between these courses is a dynamic process. The faculty teaching these courses have spent many hours reviewing course syllabi and identifying appropriate points in the course where integration of topics will be effective. They also meet regularly to discuss progress and to propose changes in the implementation of previously developed plans. This collaboration allows for continuous improvement of all classes.

\begin{tabular}{|lr|lr|lr|}
\hline \multicolumn{5}{|c|}{ Integrated Freshman Engineering Curriculum } \\
\hline Fall Quarter & Hours & Winter Quarter & Hours & Spring Quarter & Hours \\
\hline Freshman Engr 1 & 2 & Freshman Engr 2 & 2 & Freshman Engr 3 & 2 \\
\hline Math 1 & 3 & Math 2 & 3 & Math 3 & 3 \\
\hline Chemistry 1 & 2 & Chemistry 2 & 2 & Physics 1 \\
\hline Composition 1 & 3 & Chemistry Lab & 1 & Program Specific & 3 \\
\hline University Seminar & 1 & Composition 2 & 3 & & 11 \\
\hline Total Hours & 11 & Total Hours & 11 & Total Hours & 3 \\
\hline
\end{tabular}

The engineering component of the new curriculum includes extensive training in team skills as well as creative problem solving skills and engineering design. The traditional chemistry, physics, and mathematics courses are also modified where appropriate to relate topics in one course to another.

"Proceedings of the 2002 American Society for Engineering Education Annual Conference \& Exposition Copyright (12002, American Society for Engineering Education" 
The engineering course spans the first year and emphasizes problem-solving strategies by demonstrating application of these math and science principles, sometimes with laboratories, sometimes with in-class assignments. This course also includes information on engineering disciplines, communication skills, drawing and visualization, and computer tools for engineers.

The engineering math sequence in this curriculum is significantly different from that in the traditional program. The integrated curriculum uses a "just-in-time" approach to precalculus and calculus topics. Critical precalculus topics are reviewed just prior to the point in the course where that topic will be needed to fully understand a particular concept in calculus. Thus, the first year of engineering math includes both precalculus and calculus topics.

\begin{tabular}{|l|lr|lr|lr|}
\hline \multicolumn{7}{|c|}{ Table 2 } \\
\hline & Fall Quarter & Hours & Winter Quarter & Hours & Spring Quarter & Hours \\
\hline $\begin{array}{l}\text { All } \\
\text { programs }\end{array}$ & Math 4 & 3 & Math 5 & Math 6 & 3 \\
\hline $\begin{array}{l}\text { All } \\
\text { programs }\end{array}$ & Statics/strength & 3 & Electrical Engineering & 3 & Thermodynamics & 3 \\
\hline $\begin{array}{l}\text { Some } \\
\text { programs }\end{array}$ & Materials & 2 & Physics 2 & 3 & & \\
\hline \multicolumn{7}{|l|}{ Other program specific courses are also required } \\
\hline
\end{tabular}

The statics/strength course is an integration of material that is normally found in separate statics and strength courses. For example, when students learn about the concept of forces, they immediately learn about stresses and how materials are deformed by them. This course includes in-class labs and a design project.

A materials engineering course is required by most of the disciplines. The mechanical and civil engineering programs also have separate materials laboratory courses.

The math courses cover calculus, statistics and differential equations. Selected topics from elementary differential equations are taught along with calculus late in the freshman year to support physics and the sophomore engineering courses. Elementary statics concepts are covered in time to allow students to statistically analyze their engineering laboratory data. More advanced differential equations and statics concepts are covered in the sophomore math sequence.

"Proceedings of the 2002 American Society for Engineering Education Annual Conference \& Exposition Copyright @2002, American Society for Engineering Education" 


\section{Reduction in number of semester hours in our curriculum}

Prior to 1998 all engineering curricula had at least 138 semester hours. It assumed that all freshman students would start in calculus, which was rather unrealistic. Most students had to take an introductory math course which increased the defacto curriculum to 142 hours.

Louisiana Tech University operates on a quarter calendar, but teaches in units of semester hours. Students take fewer courses in a quarter than they would in a traditional semester. Class times are lengthened so that the students get the same clock time that they would under a traditional semester schedule. For example, a three semester hour lecture course meets for three seventy-five minute class periods per week, rather than the three fifty minute class periods that would be usual for a semester length class.

The creation of the freshman integrated curriculum increased the number of hours by 2 (deleting two 2 hour courses and replacing them with three 2 hour courses). The creation of the sophomore integrated curriculum decreased the number of hours by 1 (changing the first materials course from three hours to two hours). These two integrated programs would therefore increase the hours in our curriculum. We received a mandate from our governing board to revise all university curricula to a maximum of 125 hours. We therefore had to eliminate approximately 4 or 5 three hour courses. The Mechanical Engineering program decided to not just eliminate 5 complete courses from our curriculum, but to totally revise our junior and senior years course sequences. Engineering program faculty met frequently during the 1997-1998 school year to discuss various curriculum options. We worked our way through what we wanted to accomplish and eventually came up with a tentative plan. This was a very dynamic process as the freshman and sophomore college wide teams were modifying that portion of the curriculum while we were concentrating on the junior and senior years. Once the integrated curriculum was adopted, we were knew exactly what our semester hour constraints were, and we had to fine tune our plans to effectively utilize the integrated curriculum. We received permission to remain at a maximum of 128 hours.

At the same time we were doing this curriculum revision, we were revising our program objectives and developing our program outcomes (described in a different section of this paper). Decisions we made concerning our program objectives and outcomes affected the choices we made in what courses to keep, modify, delete, or create. It was not a one way effect. Our curriculum choices also helped us to clarify what we really wanted in our objectives and outcomes.

\section{Upper level curriculum changes (Mechanical Engineering examples)}

The engineering graphics and computer programming courses that were in the freshman year have been deleted. They have been replaced by a three course freshman engineering sequence which

"Proceedings of the 2002 American Society for Engineering Education Annual Conference \& Exposition Copyright $\odot 2002$, American Society for Engineering Education" 
incorporates some of the topics previously covered in those courses. Some of the programming topics have been moved into our modified numerical methods course that students take in the spring of their sophomore year. Other than rearranging the quarters some classes are taken, the change in the numerical methods course (including increasing it from 2 to 3 semester hours) was the major change we have made. One change in the sophomore integrated curriculum had significant impact to our program. This was the merging of the statics and strength courses into one course. While we are pleased with this integration, the new course does not cover as much material in 3 semester hours as two courses could cover in 6 semester hours. After taking this course our students are not adequately prepared for our junior level advanced strength course. Therefore, along with the civil engineering program, which had a similar problem, we have created a two hour intermediate strength course that follows the statics/strength course and precedes our advanced strength course.

Our junior year is shown below. New or significantly modified courses are in bold.

\begin{tabular}{|c|c|c|}
\hline \multicolumn{3}{|c|}{$\begin{array}{c}\text { Table } 3 \\
\text { ME Program Junior Year }\end{array}$} \\
\hline New Curriculum & & Comments \\
\hline Basic Measurements & 2 & converted from 3 hour to 2 hour course \\
\hline Engineering Economics & 2 & moved from sophomore year \\
\hline Thermo 2 & 2 & ne w course \\
\hline Dynamic Systems & 3 & \\
\hline Intermediate Strength & 2 & new course \\
\hline Technical Presentations & 3 & \\
\hline Computer aided modeling & 3 & new course \\
\hline Dynamics of Machine elements & 3 & moved from senior year \\
\hline Advanced Strength & 3 & \\
\hline Heat transfer & 3 & new course \\
\hline Fluid mechanics & 3 & new course \\
\hline Manufacturing & 2 & modified and moved from sophomore year \\
\hline
\end{tabular}

We have made several significant changes to our junior year. The basic measurements class has been converted from a 3 hour to a 2 hours course. We have significantly rearranged the way we teach thermodynamics and fluids. We used to have one three hour and one five hour course in these topics.

"Proceedings of the 2002 American Society for Engineering Education Annual Conference \& Exposition Copyright $@ 2002$, American Society for Engineering Education" 
We have now broken that down into three separate courses that more fit the traditional arrangement of thermo-fluids topics. The fluids course is not totally new, it is one that is now taught with the civil engineering program. The manufacturing class has been moved from the sophomore year and significantly changed. As was mentioned earlier, the intermediate strength course is brand new. Also completely new is the computer modeling course.

\begin{tabular}{|l|l|l|}
\hline \multicolumn{2}{|c|}{ ME Program Senior Year } \\
\hline New Curriculum & \multicolumn{1}{|c|}{ Comments } \\
\hline Senior Seminar & 1 & \\
\hline Thermal Design & 3 & \\
\hline Machine Design & 2 & converted from 3 hour to 2 hour course \\
\hline ME Senior Lab & 1 & \\
\hline History elective & 3 & \\
\hline Design \#1 & 2 & \\
\hline Humanities/social science elective & 3 & \\
\hline Literature elective & 3 & \\
\hline Technical Elective & 3 & \\
\hline Design \#2 & 1 & \\
\hline Humanities/social science elective & 3 & \\
\hline Arts elective & 3 & \\
\hline
\end{tabular}

Only two courses were significantly changed in senior year. The machine design course was changed to a 2 semester hour course (by removing its laboratory component). The senior seminar course was redesigned to make it more practical for our students. We changed some of its topics to include more seminars by outside speakers. Among our topics this past year were presentations by both new and experienced engineers in industry, as well as a presentation by a certified financial planner.

Similar curriculum modifications were made in all six of the engineering programs.

"Proceedings of the 2002 American Society for Engineering Education Annual Conference \& Exposition Copyright $@ 2002$, American Society for Engineering Education" 


\section{Managing the Preparation for the ABET Visit}

\section{A. Development of Program Objectives and Outcomes}

The program objectives were not created to satisfy ABET requirements, but were something that had been developed over a number of years. In 1990, the entire University entered into a self-study as mandated by our regional accreditation agency, the Southern Association of Colleges and Schools (SACS). As a part of this self-study, each program unit was called upon to develop a unique set of educational objectives. For example, the then joint Mechanical-Industrial Engineering department developed a statement of the "desired characteristics of our graduates."

Following the SACS site visit in 1995, the University and the COES began an extensive strategic planning efforts culminating in a University Strategic Plan in 1997 and a COES strategic plan shortly thereafter. In April, 1998, the programs began to prepare formally for the ABET Self-Study Report and accreditation visit in 2001 using Engineering Criteria 2000. Educational objectives were first developed by the programs in spring of 1998, with input from program advisory boards. Each of the programs developed from 4 to 6 broad objectives. Although these were reviewed and revised between 1998 and 2001, these objectives were helpful in guiding curriculum reform discussions.

The minutes of the Mechanical Engineering program faculty meetings reveal extensive ongoing discussions of the materials generated by the pilot institutions in 1997 in light of our own previously defined objectives. During this period of discussion, there were several presentations of lessons learned from the SACS self-study and the strategic planning efforts that had been completed recently. Finally, on April 28, 1998, the Educational Objectives were approved by the program faculty and posted on the Mechanical Engineering Program web page http://www.latech.edu/tech/engr/meen/meugrd.htm. They were subsequently submitted to the ME/IE Industrial Advisory Council and endorsed at their Spring, 1998 meeting.

Many of the Program Chairs and other faculty attended EC2000 training sessions during 1998-2000. Often the advice regarding assessment processes and even regarding program outcomes was conflicting. For example, the initial version of Mechanical Engineering Program Outcomes was identical to ABET Criterion $3 \mathrm{a}-\mathrm{k}$ with the addition of two outcomes taken from the ABET Criteria 8 for mechanical engineering. Upon further reflection we concluded that these outcomes may well represent good generic mechanical engineering outcomes, but they did not reflect the uniqueness of our approach at Louisiana Tech University. We subsequently modified these outcomes in November of 2000. They are also posted on our program web page http://www.latech.edu/tech/engr/meen/meugrd.htm.

Some programs attempted to write outcomes completely independent of ABET Criterion $3 \mathrm{a}-\mathrm{k}$. Eventually all of our programs adopted from 10 to 14 program outcomes that clearly reflected $3 \mathrm{a}-\mathrm{k}$, but also reflected the goals of our faculty and advisory boards for our graduating students.

"Proceedings of the 2002 American Society for Engineering Education Annual Conference \& Exposition Copyright $@ 2002$, American Society for Engineering Education" 


\section{B. Development of Assessment methods to analyze our performance (Mechanical Engineering examples)}

The Mechanical Engineering Program Educational Objectives were achieved through a combination of inputs. The most important of these are the undergraduate course curriculum and student advising, since every student is affected by these two. (Other inputs, such as participation in student societies, competitions, research projects, etc., may involve only a subset of the student body, but they give an overall tone and level of achievement which affects the entire program.) The undergraduate course curriculum is certainly the most significant contributor to achieving the Mechanical Engineering Program Educational Objectives. Over the past 20 years, the curriculum has been carefully studied in a systematic way three times, resulting in significant revisions each time. More modest changes, such as the terms during which specific courses will be offered, are made on an annual basis. The process through which both major and minor curriculum changes are made is presented in Figure 2 below.

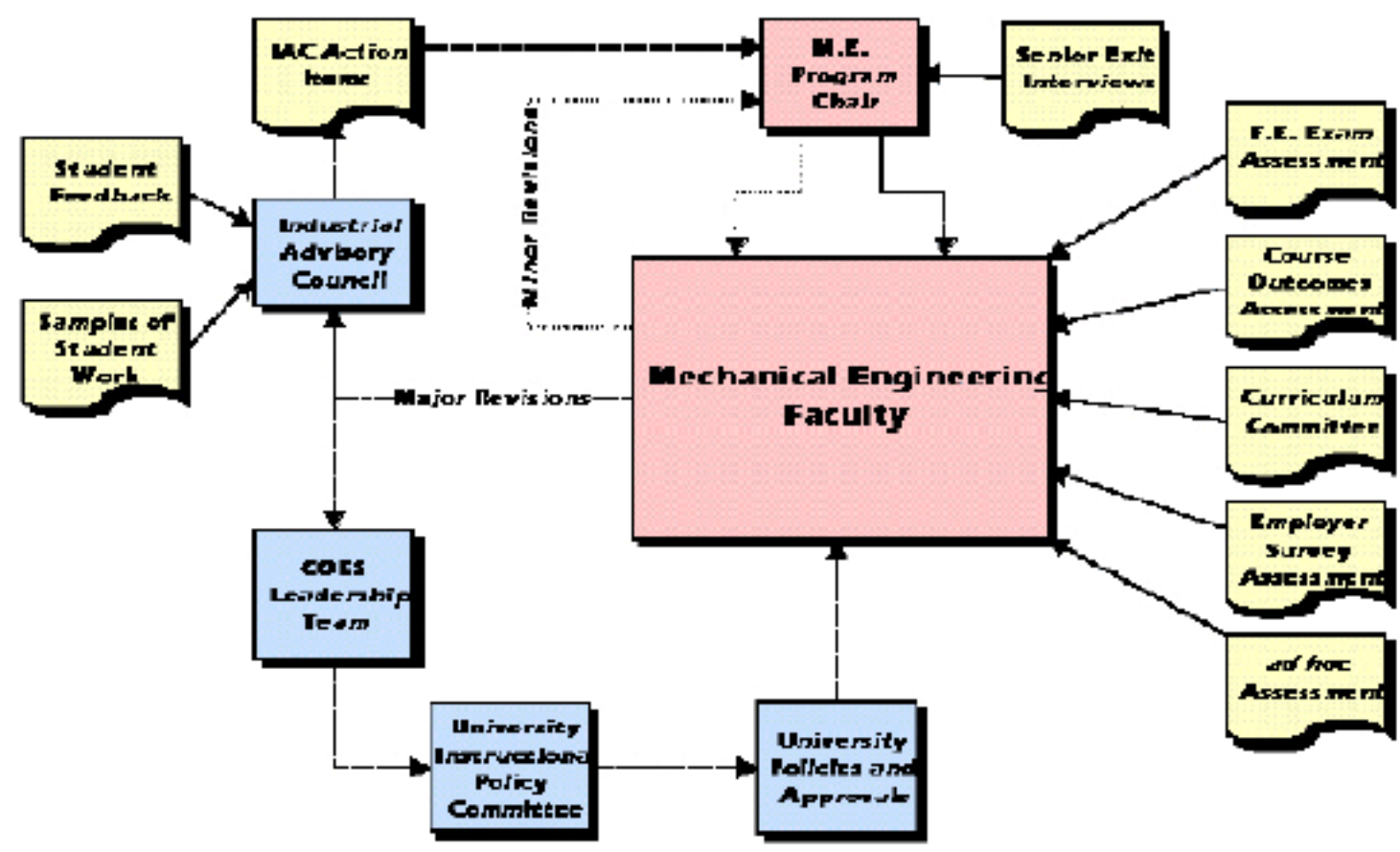

Figure 2 Process loop describing curriculum modification process in ME curriculum

There are three mains loops in Figure 2. Minor changes are those that do not require any approval by the University administration. Such changes are usually based on input by a student or faculty member

"Proceedings of the 2002 American Society for Engineering Education Annual Conference \& Exposition Copyright $@ 2002$, American Society for Engineering Education" 
or the results of a student survey. Major changes to the curriculum take two paths as indicated in Figure 2. Proposed major changes usually travel these paths more or less in parallel. Often, the timing is such that proposed changes are considered by the Industrial Advisory Council prior to being submitted to the University administration. Obviously, the path that leads through the University administration must be traversed successfully for such major changes to be approved.

We have used a number of other procedures to assess our work. One of them is the use of alumni surveys. The Mechanical Engineering Program has conducted two alumni surveys in recent years. The first survey was conducted as a part of the Southern Association of Colleges and Schools reaccreditation effort of 1995. The survey was distributed as an enclosure to the Program Newsletter. Surveys were returned by mail. The results of the 1995 survey were presented to the Mechanical Engineering Faculty and discussed. A second comprehensive survey was conducted in 1998. This survey was also distributed as a newsletter enclosure to all Mechanical Engineering alumni. Additionally, it was made available on the Mechanical Engineering Program web page for online submission. The responses to the 1998 survey were analyzed by the Mechanical Engineering Program Assessment Team and discussed by the Mechanical Engineering Faculty and the Mechanical/Industrial Engineering Industrial Advisory Council. In some of our engineering programs, the entire faculty serves as the assessment team.

In reviewing the survey data, the Assessment Team recommended that the junior-level courses (such as basic measurements and dynamic systems) continue to emphasize data acquisition and analysis. Also, the senior-level courses (such as senior lab and others) should expect that their students have background and experience in data acquisition and analysis and expect their students to demonstrate these skills independently. It is further anticipated that the more modern data acquisition systems now being used in the labs (such as basic measurements and fluid mechanics) will contribute to improving the students' impressions regarding their experience with experimental and data analysis techniques.

We have used feedback from students in our assessment in a variety of ways. The Mechanical Engineering Program uses two assessment tools targeted toward students in the last year of the curriculum. Considerable emphasis is given to the information obtained from these tools as they give the best picture of our students' perceptions of their accomplishment of our stated Program Objectives and Outcomes. The first of these senior assessment tools is a Program Objectives and Outcomes survey which is usually conducted during the fall quarter. In addition to requesting direct assessments of achievement of Program Objectives and Outcomes, the survey also requests other miscellaneous data, including job placement information. Since this survey is conducted near the end of the fall quarter when most seniors will be completing their job interviews, students will have just completed an intense period of reflection concerning their specific job-related capabilities. Thus, they are in a good position to give summative evaluations of their undergraduate experience. The senior Program Objectives and Outcomes Survey forms are processed and summarized by the Mechanical Engineering Assessment Team at the conclusion of the fall quarter and presented to the Mechanical Engineering Program faculty

"Proceedings of the 2002 American Society for Engineering Education Annual Conference \& Exposition Copyright $@ 2002$, American Society for Engineering Education" 
for discussion early in the spring quarter.

The second senior assessment tool is the Graduating Senior Exit Interview. This interview is conducted by the Mechanical Engineering Program Chair during each graduating senior's final quarter. Several formats for the interview have been tried in past years. Experience has shown that students are most responsive when interviewed in pairs or in small groups up to four. The interviews are not completely scripted, but a general outline is used for each interview. Rather than seeking summative evaluations, the Graduating Senior Exit Interview is intended to evoke specific opinions and comments that can lead to improvements in individual courses, relationships among courses, or other aspects of the Mechanical Engineering Program. The Program Chair prepares an anonymous digest of the interviews. This digest is reviewed in depth during the Mechanical Engineering Faculty Retreat, which is held at the end of the academic year.

The Industrial Advisory Council has made it a priority to meet with groups of students at each of its semi-annual meetings on campus. During the fall meeting, Council members meet with individual classes that are relatively homogeneous with respect to classification (e.g., freshmen, sophomores, juniors, and seniors). During the spring meeting, Council members meet with the officers of the various student organizations (e.g., ASME, Pi Tau Sigma, SAE, ASHRAE). No faculty are present during any of these meetings with students. On the Saturday morning following the meetings with students, the Industrial Advisory Council meets with the Mechanical Engineering faculty to summarize the major points of discussion they had with the students. These topics are addressed by the faculty in subsequent meetings and a written response is provided to the Industrial Advisory Council.

We have also used assessment based on our students performance on the Fundamentals of Engineering (F.E.) exam. As recommended by the Mechanical Engineering Assessment Plan, the faculty reviews the results of the Fundamentals of Engineering Exam that is given twice annually. Based upon the F.E. exam data some changes to further develop and improve the mechanical engineering program were implemented as well as recommendations to our students to improve the usefulness of these data in measuring student performance. We have revised the content of some courses in order to increase the amount of time spent on topics where our students scored less well.

Many of our changes in the past several years have been to individual courses. We survey the students in each course as to whether or not we have met the course objectives and outcomes.

Program changes resulting from applying the results of Program Outcomes assessment are processed using the same procedures as those used to assure Program Objectives are being attained (Figure 2). Changes are characterized as minor or major changes. Minor changes are those that can be made with relatively little impact on the rest of the program, while major changes are those that require extensive coordination.

"Proceedings of the 2002 American Society for Engineering Education Annual Conference \& Exposition Copyright $\odot 2002$, American Society for Engineering Education" 
Minor changes, such as those resulting from analysis of Course Objectives and Outcomes Surveys, are usually processed entirely by the instructor teaching the course with only an oral or summary written report to the rest of the Mechanical Engineering faculty. It is then the responsibility of the same faculty member to follow through with an assessment of the impact of the change the next time the course is taught. Such changes are noted on the summary report of the Course Objectives and Outcomes Survey and are maintained on file by the Mechanical Engineering Assessment Team. Other similar minor changes are processed through discussions in faculty meetings and recorded in the meeting minutes. A digest of all minor changes is presented to the Mechanical/Industrial Engineering Industrial Advisory Council at each of its meetings and discussed as necessary.

Major changes are defined as those which, because of their scope, cannot be implemented without approval or coordination from University officials, or, because of their impact, merit thoughtful consideration by others in the University community or the Mechanical/Industrial Engineering Industrial Advisory Council. Such major changes are proposed and discussed over an extended period and brought before appropriate stakeholders for full and complete discussion. The Mechanical Engineering Assessment Team is responsible for proposing, in advance, an assessment method that may be employed to determine how the proposed change may impact the Program Outcomes.

\section{Changes made as we did assessment}

We have made a number of changes as a result of our assessment procedures. Most of these result in changes to individual courses. Some of these are the result of the numerical scores that students give to our assessment surveys. Some of them were the result of qualitative judgements made by the professor based on student written comments. Not every change results in an overall improvement. Sometimes the change in the course does not help. This is not a serious problem, for what is important is that we are always assessing and seeking to improve.

\section{Problem of transcripts}

When the curriculum revision was occurring, we were in the middle of an ABET cycle. We did not want to be in the first year of a new curriculum during the time of the ABET visit, so we had to decide whether to implement the changes quickly (more quickly than we had planned) or wait until the ABET visit was over. We decided we did not want to wait several years to implement what we thought was an improved curriculum, so acted quickly during the 1997-1998 year to implement the new curriculum. Doing all of these changes at once was not easy, but it was probably easier than trying to make gradual changes over the course of several years.

Implementing the new curriculum when we did significantly increased the work we had to do in one

"Proceedings of the 2002 American Society for Engineering Education Annual Conference \& Exposition Copyright $\odot 2002$, American Society for Engineering Education" 
area related to the ABET visit: transcript evaluation. We implemented all of the changes essentially at the same time. This meant that many of our current students could not graduate on the old curriculum (for some of those courses had been deleted). They could not graduate entirely on the new curriculum either, for they had not taken the freshman and sophomore integrated courses. They were allowed to graduate on a modification of the new curriculum, with many course substitutions for the new courses. This meant that most of our 2001 graduates had at least 10 course substitutions in their transcript record. This made for increased complexity as we evaluated their records for graduation. It also made the requirement that we document their graduation eligibility for ABET more difficult. We had to create an additional form to document all of the changes for each student. However, many of the ABET reviewers commented that this form was very helpful in the review process.

\section{Lessons Learned}

It is clearly possible to go through a structural change, create an integrated freshman/sophomore integrated curriculum, totally revise the junior/senior curriculum, and change the way you do assessment (to fit in with the ABET EC2000 approach) at the same time, for we have done it.

We learned that making a large curriculum change shortly before an ABET visit makes preparation more difficult, for there will be many potential problems with student transcripts.

We strongly suggest that other universities set up good, repeatable assessment procedures because they help you to continually improve the education of your students. Do not set up procedures just to please the ABET evaluators. Create a system that will really help improve the quality of your program. In addition these processes, in particular advisory board feedback and student/graduate feedback, will help to accommodate other significant changes such as administrative or curriculum reform changes. If these processes really work, then satisfying ABET should not be that difficult.

The time to begin preparation for the ABET EC2000 process is immediate. Do not wait until one or two years before your next visit. Begin the preparation now. Creating the assessment process, using the assessment process, and then making changes based on your assessments takes time. It takes even more time to assess the changes that you have made.

However, we do not recommend that you try to do all four of these changes at the same time. We are not saying you should only do them at separate times, for that may significantly lengthen the time required to make the reforms you deem necessary. We suggest that you do only about two of these at a time.

\section{Bibliography}

"Proceedings of the 2002 American Society for Engineering Education Annual Conference \& Exposition Copyright $@ 2002$, American Society for Engineering Education" 
1. $\quad$ Benedict, B.A., S.A. Napper, and L.K. Guice, Strategic Structure for Strategic Outcomes, J. Engrg. Educ., pp. 227-246, April 2000.

2. Nelson, J.D. and S.A Napper, Ramping Up an Integrated Engineering Curriculum to Full Implementation, Frontiers in Education, 1999.

\section{Biographical information}

WILLIAM JORDAN is Professor and Program Chair of Mechanical Engineering at Louisiana Tech University. He has B.S. and M.S. degrees in Metallurgical Engineering from the Colorado School of Mines. He has an M.A. degree from Denver Seminary. His Ph.D. was in mechanics and materials engineering from Texas A \& M University. He teaches materials oriented courses and his main research area deals with the mechanical behavior of composite materials. He is a registered metallurgical engineer in the state of Louisiana.

MEL CORLEY, Ph.D., P.E. is a Professor of Mechanical Engineering at Louisiana Tech University. He received his B.S. in Mechanical Engineering from Louisiana Tech and his M.S. and Ph.D. degrees in Mechanical Engineering from the University of Texas at Austin. He teaches courses in mechanical systems, numerical methods, and automatic controls. He was the lead author of the Mechanical Engineering Program EC-2000 self-study which was used as a template by the other programs in the College.

STAN NAPPER received the B.S. in Biomedical Engineering in 1980 and the Ph.D. in Biomedical Engineering in 1985 from Louisiana Tech University. He is currently the Academic Director for Biomedical, Industrial, and Mechanical Engineering and Professor of Biomedical Engineering at Louisiana Tech, where he has been on the faculty since 1984. His research interests include artificial intelligence, automated ECG interpretation, and physiological modeling, but primary effort is focused on engineering education improvements. He has been an active member of the Biomedical Engineering Division of ASEE, having served in several officer positions. He is a member, and a faculty advisor, of Tau Beta Pi.

"Proceedings of the 2002 American Society for Engineering Education Annual Conference \& Exposition Copyright $@ 2002$, American Society for Engineering Education" 